\title{
A invenção da inversão: ciência, educação e lesbianidade
}

\author{
The invention of inversion: science, education and lesbianity
}

La invención de la Inversión: ciencia, educación y lesbianismo

MARLON SILVEIRA DA SILVA (iDa

MARCIO CAETANO

MARIA DA CONCEIÇÃO SILVA SOARES (iDc

\section{Resumo}

No projeto de Brasil republicano, higienista e eugenista, vários discursos defendiam a escola e a família como espaços pedagógicos de formação sexual. Para tanto, uma de suas estratégias biopolíticas de governamentalidade era produzir saberes sobre as mulheres. Considerando este cenário, temos como objetivo analisar os discursos científico sobre a homossexualidade feminina produzidos entre as décadas de 1920 e 50. Interessa-nos analisar as representações que estão presentes nesses discursos e que contribuíram na invenção daquilo que foi assimilado como a invertida sexual e/ou homossexual feminina. Para tanto, as contribuições das Análises Documentais e de Discursos de base foucaultiana foram fundamentais para examinar as publicações voltadas a identificar, tipificar e determinar as práticas educativas preventivas ou de cura ao "homossexualismo feminino". Com os dados, observou-se que o status patológico à homossexualidade feminina quando debatida a sua origem, prevenção e cura constatou-se diferenças substanciais entre os cientistas e a posição da psiquiatra Iracy Doyle, autora do primeiro livro sobre o tema no Brasil. Mesmo atribuindo à homossexualidade o título de "problema", as contribuições de Doyle apresentavam a inversão sexual feminina como uma alternativa para as mulheres

\footnotetext{
a Universidade do Estado do Rio de Janeiro (UERJ), Rio de Janeiro, RJ, Brasil. Doutorando em Educação, e-mail: marlon_Itbg@hotmail.com

${ }^{\mathrm{b}}$ Universidade Federal de Pelotas (UFPel), Pelotas, RS, Brasil. Doutor em Educação, e-mail: mrvcaetano@ufpel.edu.br

' Universidade do Estado do Rio de Janeiro (UERJ), Rio de Janeiro, RJ, Brasil. Doutora em Educação, e-mail: ceicavix@gmail.com
} 
romperem com a condição passiva de esposas e mães. Esta interpretação ia à contramão dos demais cientistas que se comprometeram em estudar a homossexualidade feminina, os quais, em seus discursos, fortaleciam as atribuições de papéis pautados pelas diferenças biológicas, reforçando as representações sociais de homens e mulheres.

Palavras-chave: Gênero. Sexualidades. Lesbianidade. Regulação Social.

\section{Abstract}

In the Brazil Republican, hygienist and eugenicist project, several speeches defended the school and the family as pedagogical spaces for sexual formation. To do so, one of his biopolitical strategies of governance was to produce knowledge about women. Considering this scenario, our objective is to analyze the scientific discourses on female homosexuality produced between the 1920s and 50s. We are interested in analyzing the representations that are present in these discourses and that contributed to the invention of what was assimilated as the inverted sexual and/or homosexual female. To this end, the contributions of Documentary Analyses and Foucaultian - based Discourses were fundamental in examining publications aimed at identifying, typifying, and determining preventive or curative educational practices for "female homosexualism". With the data, it was observed that the pathological status of female homosexuality when discussing its origin, prevention and cure, there were substantial differences between scientists and the position of the psychiatrist Iracy Doyle, author of the first book on the subject in Brazil. Even attributing the title of "problem" to homosexuality, Doyle's contributions presented female sexual inversion as an alternative for women to break with the passive condition of wives and mothers. This interpretation was contrary to the other scientists who committed themselves to studying female homosexuality, who, in their speeches, strengthened the attributions of roles guided by biological differences, reinforcing the social representations of men and women.

Keywords: Gender. Sexualities. Lesbianity. Social Regulation.

\section{Resumen}

En el proyecto brasileño republicano, higienista y eugenista, varios discursos defendieron la escuela y la familia como espacios pedagógicos de formación sexual. Para eso, una de sus estrategias biopolíticas de gubernamentalidad fue producir conocimiento sobre las mujeres. Ante este escenario, nos proponemos analizar los discursos científicos sobre la homosexualidad femenina producidos entre las décadas de 1920 y 1950. Nos interesa analizar las representaciones que están presentes en estos discursos y que contribuyeron a la invención de lo que se asimiló como la invertida sexual y/o mujer homosexual. Para ello, los aportes del Análisis documental y los Discursos basados en Foucault fueron fundamentales para examinar publicaciones orientadas a identificar, tipificar y determinar prácticas educativas que previenen 0 
curaron el "homosexualismo femenino". Con los datos, se observó que el estado patológico de la homosexualidad femenina al debatir su origen, prevención y cura mostró diferencias sustanciales entre los científicos y la posición de la psiquiatra Iracy Doyle, autora del primer libro sobre el tema en Brasil. Incluso dando el título de "problema" a la homosexualidad, las contribuciones de Doyle presentaron la inversión sexual femenina como una alternativa para que las mujeres rompan la condición pasiva de esposas y madres. Esta interpretación fue en contra de otros científicos que se comprometieron a estudiar la homosexualidad femenina, quienes, en sus discursos, fortalecieron los roles asignados por las diferencias biológicas, reforzando las representaciones sociales de hombres y mujeres.

Palabras clave: Género. Sexualidades. Lesbianidad. Regulación Social.

\section{Introdução}

No projeto de Brasil republicano, higienista e eugenista, vários discursos defendiam a escola e a família como espaços pedagógicos de formação sexual. Para tanto, uma de suas estratégias biopolíticas de governamentalidade era produzir saberes sobre as mulheres. Considerando este cenário, temos como objetivo analisar os discursos científico sobre a homossexualidade feminina produzidos entre 1920 e 50. Interessa-nos analisar as representações que estão presentes nesses discursos e que contribuíram na invenção daquilo que foi assimilado como a invertida sexual e/ou homossexual feminina. Para tal, as contribuições das Análises Documentais e de Discursos de base foucaultiana foram fundamentais para analisar as publicações sobre o tema em destaque.

Tensionando a relação direta entre as palavras e as coisas, Michel Foucault (1986) nos ajuda a entender como essa articulação não é nada direta.

[...] gostaria de mostrar que o discurso não é uma estreita superfície de contato, ou de confronto, entre uma realidade e uma língua, o intrincamento entre um léxico e uma experiência; gostaria de mostrar, por meio de exemplos precisos, que, analisando os próprios discursos, vemos se desfazerem os laços aparentemente tão fortes entre as palavras e as coisas, e destacar-se um conjunto de regras, próprias da prática discursiva. [...] não mais tratar os discursos como conjunto de signos (elementos significantes que remetem a conteúdos ou a representações), mas como práticas que formam sistematicamente os objetos de que falam (FOUCAULT, 1986, p. 56). 
Definir o conceito de discurso em Foucault não é tarefa fácil, pode-se dizer que as reflexões em torno da questão atravessam parte de suas pesquisas. Porém, chamaremos a atenção para as compreensões que nos ajudaram a refletir e analisar nosso material empírico. Para Foucault, segundo Rosa Maria Bueno Fischer (2001), não há nada escondido por trás do discurso ou entrelinhas, o que existe são enunciados e relações que são colocadas em funcionamento pelo/no próprio discurso. Essa perspectiva nos convida a refletir sobre os discursos encontrados nos diferentes textos aqui analisados, como enunciados, ou seja,

[...] considerando nossos atos elocutórios - atos enunciativos, atos de fala -, podemos dizer que esses se inscrevem no interior de algumas formações discursivas e de acordo com um certo regime de verdade, o que significa que estamos sempre obedecendo a um conjunto de regras, dadas historicamente, e afirmando verdades de um tempo. As "coisas ditas", portanto, são radicalmente amarradas às dinâmicas de poder e saber de seu tempo [...] (FISCHER, 2001, p. 204).

Interrogar a linguagem, aquilo que está posto e legitimado pelas relações de poder de um tempo histórico, não pode ser confundido como simples interpretações ideológicas. Deve-se explorar os discursos em sua peculiaridade, problematizando o dito e compreender que eles, ao mesmo tempo que nomeiam, também “inventam” o que enunciam. A linguagem será fundamental na construção do discurso que definiu a homossexual feminina. Pensar esses discursos e a forma como ganharam significado, exige que entendamos antes as reflexões propostas por Foucault (1986) a respeito do que ele chama de enunciado. Sobre isso, Fischer (2001) nos aproxima de possíveis interpretações sobre o enunciado:

Não há enunciado que não esteja apoiado em um conjunto de signos, mas o que importa é o fato de essa "função" caracterizar-se por quatro elementos básicos: um referente (ou seja, um princípio de diferenciação), um sujeito (no sentido de "posição" a ser ocupada), um campo associado (isto é, coexistir com outros enunciados) e uma materialidade específica - por tratar de coisas efetivamente ditas, escritas, gravadas em algum tipo de material, passíveis de repetição ou reprodução, ativadas através de técnicas, práticas e relações sociais [...] (FISCHER, 2001, p. 202).

Assim, é necessária a interpretação dos discursos encontrados em diferentes materiais como enunciados pertencentes a uma rede discursiva. Ou seja, um emaranhado de informações que não pode existir isoladamente, mas associado e 
relacionado a outros enunciados do mesmo discurso que se retroalimentam. Neste sentido, emergem as seguintes perguntas: quais documentos deveriam receber a nossa atenção? Que critérios utilizamos para a seleção do material a ser analisado?

No trabalho de campo, desenvolvido entre 2017 e 2018, em instituições de guarda documentais, foi possível localizar fontes que versavam sobre o corpo homossexual feminino e é por meio dessas fontes que produziremos nossas reflexões acerca das representações científicas sobre a invertida sexual. Recorremos aos fundamentos da Pesquisa Documental, propostos por Berenice Corsetti (2006), para nos auxiliar na catalogação e consequente análise dos dados, uma vez que:

O objeto da pesquisa histórica é constituído por documentos que transmitem ao historiador a realidade do passado de uma forma parcial, proporcionando um conhecimento que é "mutilado" [...]. De fato, o documento representa já uma interpretação de fatos reais elaborada por seu autor e, portanto, não deve ser encarado como uma descrição objetiva e neutra dos fatos. Por outro lado, o valor heurístico e a significação do documento dependem também da acuidade da leitura e do esforço interpretativo do historiador. Este sabe extrair de uma fonte de informações algum conhecimento útil para a compreensão de um aspecto da história humana, sob o ângulo que corresponde ao seu objeto de interesse. É esse interesse que move e orienta continuamente o pesquisador na busca de documentos [...] (MASSIMI, 1984, p. 21-22).

Nesta linha, foi necessário elaborar os seguintes eixos de análises das obras: 1) formação acadêmica e filiação teórica da autoria e 2) apresentações da homossexualidade feminina. Feito os exercícios que subsidiaram a produção e análise dos dados, de modo a atender os objetivos descritos, dividimos o artigo em três seções. Na primeira, buscamos debater as contribuições dos Estudos Foucaultianos para o tratamento e análise dos dados. Na segunda seção, debatemos as orientações produzidas pelos saberes Médico e Jurista sobre a homossexualidade feminina. Na seguinte seção, analisamos os discursos científicos direcionados ao meio familiar, buscando em suas expectativas a orientação de condutas sexuais às meninas. Por fim, as conclusões.

\section{Michel Foucault e suas contribuições}

Ao falarmos de História da Sexualidade ou História da Educação, ou, ainda, da História das redes de discursos que unem essas temáticas, muitas são as 
perspectivas teóricas que se apresentam. Entretanto, para o desenvolvimento deste artigo, tomaremos como referência os estudos e pesquisas de base foucaultiana. Dessa forma, foram eleitos alguns conceitos que possibilitaram a promoção da discussão: Governamento, Relações de Poder e Biopoder (FOUCAULT, 1987; 1999; 2004). A eleição foi feita por estarem estes intimamente relacionados entre si e corresponderem às distintas tecnologias utilizadas em diferentes tempos e espaços para tentar se obter a regulação e o controle dos indivíduos (FOUCAULT, 1999).

Ao fazer uma análise crítica da Modernidade, Foucault (1987) nos oferece algumas ferramentas de análises que contribuem para que possamos realizar nossas reflexões. Suas pesquisas em torno das diferentes instituições que historicamente serviram para regular e disciplinar, tais como a igreja, o manicômio, a prisão, a escola, entre outros, nos ajudam a entender as estratégias e tecnologias de poder utilizadas pelo discurso científico brasileiro entre as décadas de 1920 e 1950 para a construção dos marcadores de identificação da inversão sexual feminina. No caso desta pesquisa, a ciência, a família e a escola ganham atenção, visto que eram também responsáveis pela produção e regulação de indivíduos.

Ao analisar os discursos sobre a inversão sexual feminina e a forma com que associavam à educação a corresponsabilidade de produzi-la, resta-nos trazer os dispositivos condicionantes que, articulados, possibilitaram a emergência das verdades científicas. Um desses dispositivos, que teve centralidade nesta pesquisa, foi a sexualidade. Neste texto, ela é entendida como um dispositivo histórico, atravessado e alimentado por estratégias de saber-poder que atuam basicamente sobre os corpos subjetivando-os e objetivando-os. Neste contexto, entende-se por subjetivação as "práticas e processos heterogêneos por meio dos quais os seres vêm a se relacionar consigo mesmos e com os outros como sujeitos de certo tipo" e objetivação o "modo como o sujeito pôde se tornar um objeto para o conhecimento" (ROSE, 2001, p. 36).

Ao refletirmos sobre subjetivação e objetivação, o debate em torno do saber psiquiátrico e o poder nos parece um bom exemplo. Jurandir Costa (1989) traz a compreensão de Foucault a respeito dessa relação:

Para Foucault, a história da Psiquiatria não pode ser corretamente analisada a partir de conceitos psicológicos ou sociológicos. Só o conceito de "poder", em suas diversas 
modulações históricas, permite compreender a natureza da prática e das teorias psiquiátricas, desde suas origens até seu estágio atual [...] (COSTA, 1989, p. 10).

Desta forma, parece nítida a ligação entre poder e o saber psiquiátrico, o que nos leva a refletir sobre o conceito de governamento. Da mesma forma que na década de 1960 "a arqueologia dos discursos científicos ocupou os interesses de Foucault” (CASTRO, 2014, p. 48), a partir da década de 1970, o filósofo investiu como tema central de seus estudos e pesquisas o detalhamento da descrição dos dispositivos de poder centrados no governo dos indivíduos e das populações. Ao se voltar para a história da loucura e do crime, Foucault teve como objetivo demonstrar por meio dos indivíduos excluídos, o normal. A noção de poder, com isso, ganha um novo desdobramento: a racionalidade política do conceito de governo.

Poder disciplinar e biopoder figuram entre as diferentes configurações de poder apresentadas por Foucault. Segundo ele, o poder disciplinar ganha importância estratégica nas relações modernas depois do século XIX, exercendo papel fundamental sobre a loucura, a delinquência e a infância, enquanto o biopoder se dirige aos cuidados, aos fenômenos ligados à população. Esses conceitos nos permitem analisar os discursos científicos enquanto dispositivos de subjetivação e de governamento. Nessa direção, o conceito de governamentalidade torna-se central nessa discussão, uma vez que governar "é sempre um difícil e versátil equilíbrio de complementaridade e conflito entre técnicas que asseguram a coerção e processos por meio dos quais o 'eu' é construído e modificado por si próprio" (FOUCAULT, 1993, p. 207).

Pensar os discursos produzidos e difundidos em torno do corpo homossexual feminino, dividindo os indivíduos entre normais e anormais, nos aproxima da compreensão foucaultiana sobre os regimes de verdade, tendo como objetivo a produção da verdade última e definitiva sobre o mundo físico e social (FOUCAULT, 1997). Esses regimes são, no caso deste artigo, os discursos médicojurídicos que, ao estarem carregados de redes de significados, produziram representações sobre a homossexualidade feminina.

Essa histórica relação de poder entre indivíduos e instituições nos leva a refletir sobre os discursos científicos que, no decorrer do século XIX, tornaram-se a 
autoridade no estudo do corpo e da forma, e como este último deveria regular os indivíduos através do estabelecimento da normalidade definida por meio da materialidade do corpo. Conforme nos alerta Foucault (1987):

[...] diferentemente da disciplina, que se dirige ao corpo - à vida dos homens, ou ainda, se vocês preferirem, ela se dirige não mais ao homem-corpo, mas ao homem vivo, ao homem ser vivo; no limite, se vocês quiserem, ao homem-espécie. Mais precisamente, eu diria isso: a disciplina tenta reger a multiplicidade dos homens na medida em que essa multiplicidade pode e deve redundar em corpos individuais que devem ser vigiados, treinados, utilizados, eventualmente punidos. $\mathrm{E}$, depois, a nova tecnologia que se instala se dirige à multiplicidade dos homens, não na medida em que eles se resumem em corpos, mas na medida em que ela forma, ao contrário, uma massa global, afetada por processos de conjunto como o nascimento, a morte, a produção, a doença, etc. (FOUCAULT, 1987, p. 289).

Pode-se dizer que os mecanismos de normalização disciplinar, somados às técnicas de biopoder, tornaram-se responsáveis pela objetivação e subjetivação dos indivíduos. O conceito de poder em Foucault (1986) pode ser entendido como algo que permeia todas as relações. Está capilarizado. Saber e poder inserem-se em uma mesma relação. Para o poder funcionar, é necessário acionar os chamados regimes de verdades, dito de outro modo, é necessária a produção de uma série de discursos que estabeleçam "a verdade”, os quais irão autorizar que certas coisas sejam ou não pensadas e ditas. Portanto, a produção do saber e da "verdade" está diretamente ligada ao exercício de poder, da mesma forma que o poder não pode ser exercido sem a produção desses saberes. Logo,

Nenhum saber se forma sem um sistema de comunicação, de registro, de acumulação, de deslocamento, que é em si mesmo uma forma de poder, e que está ligado, em sua existência e em seu funcionamento, às outras formas de poder. Nenhum poder, em compensação, se exerce sem a extração, a apropriação a distribuição ou a retenção de um saber. Nesse nível, não há o conhecimento, de um lado, e a sociedade, do outro, ou a ciência e o Estado, mas as formas fundamentais do "saber-poder" [...] (FOUCAULT, 1986, p. 19).

Desta forma, o biopoder e o poder disciplinar surgem como tecnologias que consolidam a sociedade de normalização e são complementares, uma vez que as estratégias de normalização do anormal (neste caso, as mulheres homossexuais) buscam amenizar o risco social de sua existência por meio de mecanismos de segurança coletiva. O objeto do biopoder é a vida, um poder que normaliza. Nessa 
perspectiva, é possível pensar a anormalidade (desviantes da norma) e tudo que se diz/escreve sobre ela, como estratégias úteis e sutis para que a norma seja reforçada e permaneça como referência. Ancorados no entendimento de "anormalidade", foram elaborados os discursos sobre os corpos das mulheres homossexuais durante a maior parte do século XX. Sob uma perspectiva de diagnóstico, correção/tratamento e prevenção, foram empreendidos estudos e pesquisas científicas que tinham como principal objetivo investigar as possíveis causas da anomalia.

O conceito de ciência para este artigo deve ser restrito para o de Ciência Sexual, ou, nas palavras do próprio Foucault "Scientia Sexualis". Para Foucault (1988), o biopoder teria se desenvolvido em duas direções: a anátomo-política dos corpos e a regulamentação da população, que, a partir do século XIX, se fundiram, constituindo assim uma grande tecnologia de poder: o dispositivo da sexualidade.

As disciplinas do corpo e as regulações da população constituem dois pólos em torno dos quais se desenvolveu a organização do poder sobre a vida. A instalação durante a época clássica, desta grande tecnologia de duas faces - anatômica e biológica, individualizante e especificamente, voltada para os desempenhos do corpo e encarando os processos da vida - caracteriza um poder cuja função mais elevada já não é matar, mas investir sobre a vida, de cima para baixo [...]. (FOUCAULT, 1999, p. 131).

Segundo o filósofo, a produção da verdade sobre o sexo passou por dois grandes procedimentos: a Scientia Sexualis (Ocidente) e a Ars Erotica (Oriente). A primeira (que nos interessa) foi desenvolvida a partir do século XIX com a função de controlar os corpos de homens e mulheres. Tal controle, inicialmente era exercido pelo ato da confissão (poder pastoral), em que a religião se tornava peça fundamental nesse processo. Já no século XX, a confissão foi substituída pela Medicina, a Ciência (mais precisamente as Ciências da Saúde) foi a autorizada a exercer a "verdade" sobre o sexo, instituindo o normal/anormal. A ciência com seu poder-saber disciplinar difundiu o sexo como um produto regulado, ou seja, inventado. Ela também instituiu, com esse processo, uma política da sexualidade.

Sendo o corpo a base por meio do qual são marcadas as diferenças e daí deriva a ideia de comportamento, ele é entendido como a plataforma da normalidade e anormalidade. Neste sentido, enquanto dispositivos de subjetivação e 
de governamento, entendemos que os discursos produzidos sobre o corpo da mulher homossexual produziram representações e, com isso, classificaram-no. Dessa forma, ao nos voltarmos para os discursos produzidos pela ciência enquanto construto cultural de determinados campos de saberes, é possível refletir sobre o quanto esses discursos operaram como verdadeiras usinas no processo de formação, subjetivação e fabricação de identidades, a partir de representações por eles criadas.

\section{O espaço escolar e o governo de condutas}

Embora a homossexualidade feminina tenha recebido pouca atenção se comparada à masculina, até a metade do século XX algumas pesquisas abordaram a temática. Baseados em pesquisas desenvolvidas pelos médicos Henry Havelock Ellis, Césare Lombroso e Gregorio Marañon, tanto intelectuais brasileiros/as ligados aos saberes jurídicos como médicos buscaram identificar as causas da homossexualidade feminina e suas possíveis formas de reversão, a exemplo de Afrânio Peixoto, Leonídio Ribeiro e Iracy Doyle.

A importância do Direito e da Medicina na produção historiográfica da primeira metade do Século XX sobre o Brasil nos leva a compreender que não apenas os espaços públicos foram regulados, mas o comportamento dos indivíduos. No discurso civilizatório brasileiro, a autoridade e voz dadas às ciências médicas e jurídicas se somou a outras instituições, como a escola e a família, que serviram como importantes porta-vozes dos discursos referenciados nos âmbitos higienista e eugenista. Segundo Giselle Reis (2006, p. 36), “o foco de preocupação do movimento higienista era a descoberta das doenças que colocavam em risco a saúde pública", sendo que:

[...] a Medicina das primeiras décadas do século XX estava influenciada pela ideologia da higiene e raça e a formação e atuação dos médicos eram fundamentadas em autores europeus a ela adeptos e aos eminentes médicos brasileiros que trouxeram a eugenia e o higienismo para o Brasil [...] (REIS, 2006, p. 38).

Baseados em pesquisas estrangeiras, médicos e juristas brasileiros encontraram no espaço escolar o ambiente propício para a divulgação e efetivação de seus estudos. Segundo Maria Stephanou (2009): 
Os discursos médicos não se restringem a defender uma bandeira genérica de educação e saúde como solução aos problemas nacionais. Há uma intensa discussão sobre qual saúde e qual educação. Não apenas uma saúde física, mas mental, moral e intelectual. Não apenas uma educação intelectual, mas física, mental, moral e sexual. Nesse período, médicos brasileiros ocupam-se cada vez mais em discutir os conteúdos e objetos de ensino, os procedimentos pedagógicos, a avaliação, o exemplo do professor, a materialidade e a salubridade das escolas, os pressupostos teóricos dos pedagogos (STEPHANOU, 2009, p. 145)

Ao voltarmos à importância da Medicina e do Direito, torna-se indispensável localizarmos a escola nessa rede que se constituiu como um dispositivo de idealização da feminilidade e masculinidade, considerando que, por meio dela, os discursos médico-jurídicos buscaram agir durante a maior parte do século XX na regulação de crianças. Isso nos reconduz ao conceito de Governo elaborado por Foucault (1999), em que esse é concebido como um emaranhado de programas e estratégias racionalizadas para a "condução da conduta". A Governamentalidade, neste caso, se refere à emergência de racionalidades políticas, ou mentalidades de governo, no qual a conduta passa a ser uma questão de administração calculada ao alcance de seus objetivos. Ou seja, podemos entender governo aqui como algo que indica uma perspectiva a partir da qual se pode tornar inteligível a diversidade de tentativas feitas por diferentes tipos de autoridades para agir sobre as ações das pessoas, buscando atingir objetivos como prosperidade nacional, harmonia, virtude, produtividade, ordem social, disciplina, etc.

Esse entendimento de governo como mecanismo destinado a conduzir as condutas, leva-nos a compreender a forma como ocorre o que Foucault (2004) denominou de processos de subjetivação e de objetivação, em que "os processos de subjetivação e objetivação que fazem com que o sujeito possa se tornar, na qualidade do sujeito, objeto de conhecimento" (FOUCAULT, 2004, p. 236). Ao buscar compreender os discursos onde as pessoas são, ao mesmo tempo, objetos e produtoras de conhecimento, torna-se possível pensá-las como efeitos das relações de saber e poder.

Com o desenvolvimento de pesquisas voltadas à sexualidade, não tardou para que a Educação se tornasse alvo de investimentos que tinham como foco o ajustamento sexual (CAETANO; BECK, 2014; CAETANO, 2016). Como nos 
alertou Foucault (1999, p. 141), "O dispositivo da sexualidade deve ser pensado a partir das técnicas de poder que lhe são contemporâneas". No seguimento surgiram, nesse período, manuais — voltados para a família e docentes — que incluíam conselhos médicos e morais. Dentre esses, destacamos o livro "Os filhos — sua preparação para a vida”, do médico francês Victor Pauchet, que afirmava: "a educação sexual deveria merecer mais atenção por parte de pais e educadores, dada a importância que o sexo tem na vida do indivíduo. Em quase todos os lares e escolas é tabu falar em sexo" (PAUCHET, 1930, p. 11). Não diferente, o médico brasileiro Afrânio Peixoto, no livro Eunice ou a educação da mulher (1944), também chamava a atenção para a importância da educação sexual familiar e escolar:

A educação sexual que pais e mestres não querem dar recebem as crianças onde não devem. É a falência da educação, é a má educação sem ela se pais e mestres fazem tanta relutância é que não foram bem-educados sexualmente e sabem "da missa" a metade [...] (PEIXOTO, 1944, p. 264).

A importância dessa orientação pode ser verificada em outros livros destinados à Educação, como encontrado no prefácio escrito pelo doutor José Adeodato Filho (1954), no livro Educação Sexual, de Margarida Neves. No texto, Adeodato Filho reforçava: "É útil, sim que os adultos, sobretudo as professoras e mães de família, tenham uma noção mais exata do verdadeiro sentido da educação sexual, para poder orientar as crianças gradativamente nas várias etapas de seu desenvolvimento" (NEVES, 1954, p. 186). O que será reforçado pela própria autora do livro:

Se bem que haja muita controvérsia a respeito do assunto, alguns pontos já se definem claramente, quanto às causas que podem levar ao homossexualismo. No entanto, a maioria dos educadores vive à margem de tais conhecimentos ou os repele terminantemente. Por isso, vezes sem conta, quando um caso se apresenta ao especialista, está irremediavelmente perdido - por ser tarde demais, ou porque os educadores negam o que lhes é pedido [...] (NEVES, 1954, p. 197).

Como visto, aos/às educadores/as também era colocada a responsabilidade pelo surgimento do homossexualismo, uma vez que, sabendo das “causas", estes poderiam evitar desde cedo que estudantes se interessassem por práticas sexuais consideradas anormais. Segundo a autora, o não comprometimento da escola poderia levar a casos irreversíveis. Cabe destacar também que o termo 
"homossexualismo" foi hegemonicamente usado pela medicina até 1990, ano em que deixou de ser considerado doença pela Organização Mundial da Saúde.

Mais do que uma educação sexual atenta à formação adequada e ao bom desenvolvimento de estudantes, as escolas foram interpeladas também por serem consideradas espaços de risco para o aparecimento da inversão sexual feminina, mais precisamente, instituições como internatos e colégios de freiras. O médico e psicólogo britânico Henry Havelock Ellis (1932) afirmou no seu livro, Inversão Sexual que:

As amizades ardentes que as meninas criam nas escolas e nos pensionatos, entre si e com as mestras, constituem assunto de interesse psicológico considerável e grande valor prático. Esses amores infantis, meio termo entre a amizade e a paixão sexual, encontram-se em todos os países onde as meninas são colocadas juntas para a instrução, e os sintomas são regularmente uniformes, ainda que variando de intensidade e de caráter, segundo os tempos e os lugares, tomando, às vezes, forma epidêmica [...] (ELLIS, 1932, p. 134).

Fica nítida a preocupação de Ellis em advertir à sociedade a respeito da origem da inversão e da responsabilidade, não só da escola, mas da família, os quais deveriam ficar atentos desde os primeiros anos da vida escolar das crianças. Segundo o médico, esses comportamentos dúbios seriam despertados através da convivência, não apenas com as colegas, mas também com as próprias professoras, o que tornava estes tais espaços foco de extrema preocupação. No que diz respeito à influência desses espaços no desenvolvimento da inversão sexual nas meninas, o médico brasileiro Viveiros de Castro (1934) também chamava a atenção para:

Os internatos: Si a vida em commum é perigosa aos rapazes, ainda mais terrível se torna para as moças por causa da natureza essencialmente affectiva da mulher. Ligações se travam entre elas, intimas e estreitas, apaixonadas e vivas. São a princípio platônicas e inocentes, mas depois, com o despertar dos sentidos, com a curiosidade sexual que a puberdade acende, podem facilmente degenerar em amores lesbios. E basta em um collegio uma menina pervertida para contagiar 0 vicio, por mais severa que seja a vigilância. A infancia é principalmente curiosa e atormentada do desejo de ser considerada já experiente e sabia. Todas por estes motivos querem experimentar a sensação nova que incendeia e abraza, a fim de serem logo consideradas mulheres (CASTRO, 1934, p. 199).

No discurso do médico, a soma da condição afetiva "natural" da mulher à curiosidade sexual da fase da puberdade e à presença de uma "pervertida" seria a 
chave para o desenvolvimento da inversão nas meninas que, ressalta o médico, escaparia até mesmo do controle da mais severa vigilância. $\mathrm{Na}$ mesma direção, Peixoto (1936) também chama a atenção para o período da puberdade, em que:

A eclosão da puberdade dá, às meninas, uma tristeza passiva, nostálgica, mística, que determina exageros sentimentais pelas camaradas ou pelas mestras. As impressões morais aí são tão vivas que, segundo uma estatística de Heller, sobre quarenta suicídios de moças, trinta e cinco se dão durante a puberdade (PEIXOTO, 1936, p. 183).

Tanto no discurso de Ellis, quanto no de Castro e de Peixoto, é verificável a naturalização das meninas como pessoas mais sentimentais e afetivas, ou seja, a "condição natural" feminina de passiva, neste caso (e talvez, somente neste), poderia ser algo negativo, um fator de risco que propiciaria os envolvimentos afetivo-sexuais com pessoas do mesmo sexo. Nessa mesma direção, Hélio da Motta alerta:

Nascem os factores externos no ambiente familiar, nas convivencias malsãs, nas aproximações com indivíduos de sexo dubio, nos ajuntamentos das corporações quaesquer que sejam, na educação, em summa, despertando uma orientação sexual anormal, por estímulos a uma atividade hormonal opposta e latente. Da mesma fórma, quando esses agentes são evitados e seleccionados e a norma educacional obedece a um rythmo favorável ao desabrochar do instinto, a polarização heterosexual se faz normalmente gradual e precisa (MOTTA, 1937, p. 46).

No discurso de Motta, ao se aproximar das correntes que defendiam a origem do bomossexualismo feminimo como proveniente de fatores externos, chamando a atenção para o risco que alguns espaços representavam, somados a uma educação adequada, a heterossexualidade seguiria seu "rythmo favorável", quer dizer, predestinada e condicionada ao sexo biológico.

Identificada a escola como um local de risco para o desenvolvimento do comportamento considerado inadequado, esta deveria sofrer maior vigilância por parte do saber cientista que passara a alertar ainda mais pais, mães e docentes a respeito desse perigo. A escola apresentava-se como um local fecundo para a vigilância e legitimação de práticas normativas, pois, historicamente, era um lugar de disciplina e regramento de corpos e mentes. Segundo Foucault (1987, p. 133):

[...] como se pode ter domínio sobre o corpo dos outros, não simplesmente para que façam o que se quer, mas para que operem como se quer, com as técnicas, 
segundo a rapidez e a eficácia que se determina. A disciplina fabrica assim corpos submissos e exercitados, corpos dóceis.

Nesse sentido, ao buscar silenciar os corpos e torná-los dóceis, a escola possuía o poder de decisão e, dessa maneira, determinava o que ensinar, quando ensinar e como ensinar, possibilitando seu domínio no processo de aprendizagem e na subjetivação dos corpos. Sendo assim, o ensino tornava-se em apenas uma via, sem o retorno do questionamento, da dúvida, não possibilitando aos/às estudantes, ao menos em suas expectativas, a descoberta de novas possibilidades.

As discussões em torno da escola mista (classes compostas por meninos e meninas) foram uma das que estavam nas pautas dos políticos e demais pesquisadores/as da educação brasileira desde o final do século XIX. Muitos/as defensores/as da continuidade da educação dividida por sexo baseavam-se em princípios morais, ancorados em valores religiosos, ressaltando e legitimando uma educação voltada para as "atribuições naturais" de cada sexo (ALMEIDA, 2005).

É nesse contexto em que os saberes da Medicina ganharam sua importância no espaço escolar. Mais do que alertar, era necessário orientar adequadamente estudantes para a sexualidade considerada correta, normal, emergindo, então, uma série de livros voltados para a orientação escolar e, mais especificamente, para a Educação Sexual. Esses saberes específicos sobre a Educação Sexual não poderiam ser pensados de forma isolada das outras dimensões, pois precisava ser legitimada por outros fatores como a religião e os valores morais vigentes. No livro Orientação Sexual, a pesquisadora Isabel Junqueira Schmidt (1942) chama a atenção para os objetivos da orientação moral e religiosa:

$\mathrm{Na}$ escola secundária brasileira, a orientação ética ou moral terá por objetivo inculcar nos adolescentes os princípios básicos normativos que devem reger o comportamento humano. A orientação religiosa visará fortalecer, na alma adolescente, os ensinamentos religiosos recebidos na família, bem como auxiliar o jovem a vencer as dificuldades peculiares à idade, na aceitação das verdades eternas (SCHMIDT, 1942, p. 79)

Sobre a função disciplinar dessa orientação religiosa e sua importância na educação, a autora ainda destaca: 
Função disciplinadora da orientação moral e religiosa - Já temos visto que as causas principais dos distúrbios da adolescência provêm da sua desadaptação, isto é, da sua falta de disciplina física e psicológica às imposições novas que a idade acarreta. Disciplinar um adolescente é, consequentemente, facilitar-lhe a adaptação ao meio social, além de ser fator de monta no desenvolvimento de suas faculdades intelectuais [...] (SCHMIDT, 1942, p. 81-82).

Através destes mecanismos de disciplina, uma série de regras e normas deveriam ser investidas sobre os corpos. Tal empreendimento possibilitaria uma separação objetiva entre pessoas consideradas normais e anormais. Tanto que:

É indispensável, além disso, que a educação sexual se faça na escola, somente quando não tiver sido feita, ou bem feita, dentro da família, pois são os pais os que têm a maior autoridade para tratar da questão. O orientador ver-se-á, no entanto, a braços com problemas originados, não raro, na má compreensão ou no mau emprego do instinto sexual nascente. Apontar aos adolescentes seus perigos e inconvenientes será o primeiro cuidado do orientador, pois muitas vezes as informações que chegam ao jovem sobre estes assuntos, são deturpadas e erradas fazendo-o às vezes incidir em faltas, apenas por não estar bastante esclarecido [...] (SCHMIDT, 1942, p. 97).

O discurso de Schmidt, somado ao dos demais intelectuais aqui trazidos, nos leva a refletir sobre o quanto as questões morais e religiosas deveriam estar presentes na formação das crianças. Indo de encontro a essas compreensões, Iracy Doyle (1956) chama atenção ao dizer que a:

[...] ciência, embora se orgulhe do seu liberalismo, ainda não se libertou completamente dos valores de natureza ética e moral, e porque não dizer religiosa, que fazem parte do acervo cultural de todos os homens do nosso grupo, inclusive dos intelectuais (DOYLE, 1956, p. 15).

No trecho parece ficar nítido a autocrítica feita pela doutora a respeito das questões de ordem moral que envolviam a ciência de seu tempo e os/as intelectuais que eram seus/suas porta-vozes. A autocrítica não se limitava às compreensões da sua área (a Medicina) em torno das inversões sexuais, ela ia mais além: "Mesmo nos livros de ciência, encontramos argumentos que mais se coadunam com a atmosfera das nossas côrtes de justiça, conservadoras por excelência e mais preocupadas em reprimir comportamentos anti-sociais do que em compreendê-los" (DOYLE, 1956, p. 15).

Pode-se dizer, que as práticas pedagógicas escolares, presente em livros e manuais voltados para a educação e que tinham como objetivo a formação de um 
corpo escolar saudável, caminhavam na direção de reforçar ensinamentos androcêntricos e patriarcais, necessários para a manutenção da sociedade moderna no interior daquilo que era desejado pelo discurso hegemônico da ciência brasileira. Nesse cenário normalizador e normatizador, a escola passa a ter a corresponsabilidade de evitar a inversão sexual, tanto a masculina quanto a feminina.

\section{O espaço familiar e 0 alicerce da sexualidade}

As transformações ocorridas nas grandes cidades no século XIX estabeleceram uma nova ordem social no Brasil. Em contrapartida à família patriarcal como resquício colonial e escravista, emerge o modelo de família burguesa orientada pela divisão socioeconômica do trabalho produtivo e reprodutivo, mantendo, inclusive, sua base androcêntrica. De forma a estabelecer e reforçar esses modelos, o discurso médico e jurídico sobre a família burguesa, somado à escola, também se voltou para a prevenção da homossexualidade feminina e direcionamento e orientação para a sexualidade normalizada (NOGUEIRA, 2005). Nesse sentido, a base moral-religiosa-patriarcal da sociedade brasileira definiu que caberia a mulher ser a guardiã do lar, responsável central pelas condutas física e moral das crianças. As pesquisas que trataram do comportamento sexual (crianças/adolescentes/homens/mulheres) foram além da performatividade do corpo e do espaço escolar e passaram a observar a esfera familiar, devendo ela, também, ser vigiada para que se mantivessem as ciências eugenistas e higienistas. Em outras palavras, se os espaços públicos e a escola deveriam receber a atenção de uma ciência eugenista e higienista, a vida familiar precisava igualmente ser vigiada. Segundo Rachel Soihet (1989, p. 113): “[...] a higienização da família com vistas ao estabelecimento da saúde física e psíquica, garantindo uma prole saudável e uma futura classe dirigente sólida e respeitosa das leis, dos costumes, das regras e convenções, é o objetivo".

Como fora dito antes, era necessário que os diferentes saberes responsáveis pela elaboração dos comportamentos normais se articulassem para que esses objetivos fossem alcançados. A intelectualidade brasileira que se encarregava da invenção da patologia da homossexualidade feminina também voltara-se para as 
possíveis formas de prevenção da inversão, a exemplo de Leonídio Ribeiro (1938), que destacava:

[...] são indispensáveis nos casos em que se mostram evidentes as influências do máu ambiente familiar, não só desencadeando, como alimentando ou agravando, as tendências e predisposições ligadas a causas de natureza congênita. Para isso, é indispensável o estudo feito por especialistas da personalidade da creança, máxime de suas doenças físicas, das aptidões, e do caráter, quer esteja sofrendo a influência do meio familiar, da escola ou dos internatos. Só assim será possível o conhecimento de cada caso concreto, não só do ponto de vista medico, como psicológico e pedagógico (RIBEIRO, 1938, p. 177).

Mesmo sendo Ribeiro defensor da ideia de que a homossexualidade tinha origens endócrinas, ele acreditava que o desvio poderia ser potencializado pelas questões socioambientais. O que corrobora com Willem Stekel, o qual Ribeiro considerava um dos grandes mestres da psicanálise:

Afirmo que ninguém nasce homossexual, mas se torna homossexual, em virtude de uma educação errada. [...] Posso provar como a acumulação de erros na educação de uma criança a empurra numa direção homossexual. [...] A relação de forças entre o pae e a mãe representa também papel importante. Atraz da homossexualidade oculta-se o medo, em face da mulher. Nos lares em que a mãe é senhora absoluta, pode se formar, na alma do menino, uma tendência a nunca se submeter a uma mulher (STEKEL, 1936. p. 176).

A importância da educação, tanto escolar quanto familiar no processo de formação, aparece em vários momentos no discurso do médico:

As observações e pesquisas de muitos anos, que realizei, sobre o assunto, me convenceram de que as influências da educação são decisivas, no aparecimento da homossexualidade. Por isso, desejo alertar os pais para que evitem os erros pedagógicos que irão privar os jovens dos elementos capazes de permitir a formação da sexualidade normal. É um perigo orientar a criança em hábitos do sexo oposto [...] (RIBEIRO, 1935, p. 92).

Cabe ainda destacar que Ribeiro foi um dos defensores da escola mista como alternativa à prevenção da homossexualidade, uma vez que desta forma coibiria o contato físico entre crianças do mesmo sexo. A influência do meio social/cultural na formação da homossexualidade era reforçada pelo médico, daí a importância de chamar a atenção dos pais e mães para isso. A responsabilidade da escola era dividida com a família, porém a figura da mãe era ressaltada e surge em muitos 
discursos como $\mathbf{a}^{1}$ responsável pelo sucesso ou falência da criação considerada adequada, normal. Ao chamar de "conceitos admiráveis de Marañon", Ribeiro chama a atenção para os escritos do autor quando afirma que:

A vida sexual deve ser considerada como uma sagrada necessidade, fonte que é das mais nobres alegrias do homem, e, por isso mesmo, carecendo de ser reservada para uma idade propicia e não malbaratada, desde os primeiros tempos de puberdade. A mãe - suprema escultora da alma dos filhos - é quase sempre a responsável, atrevemo-nos a afirma-lo, da homossexualidade e, em geral, dos demais transtornos do instinto de um varão [...] (RIBEIRO, 1935, p. 103).

Ao trazer Marañon, Ribeiro reforça essa compreensão em torno da mãe como a responsável pelo futuro das crianças. Em seu livro Eunice ou a educação da mulher, o médico Afrânio Peixoto (1944) também afirma: “A educação é uma longa sequência de atos e hábitos, ordenados e úteis. A mãe educada começou a educar a sua derivação, o filho, que cria sadiamente nas suas entranhas e criará sadiamente vindo à luz: tudo isto é educação” (PEIXOTO, 1944, p. 268).

A criação "sadia", obviamente, estava associada à criação e educação a partir das expectativas assumidas em torno dos papéis socioculturais definidos pelos sexos biológicos das crianças, de forma a direcioná-las para a sexualidade "normal", através de atividades que reforçassem as expectativas desenvolvidas por homens e mulheres. Dito de outra maneira, de forma a evitar o desenvolvimento da homossexualidade, era necessário educá-las em hábitos "naturais" de seu sexo biológico. Hábitos esses que reforçavam o papel da mulher como esposa, mãe e cuidadora.

No livro A creança Problema, o médico Arthur Ramos (1939) seguia na mesma direção:

A aversão da mulher ao homem pode estar ligada ainda à hypothese psychanalysta de que a mulher considera a feminilidade uma castração, uma mutilação, e cresce dentro deste complexo de inferioridade. Ella refugia-se então na amizade homossexual, que pode ter ou não tintas eróticas. Na adolescência, isso é muito comum nessas amizades apaixonadas, principalmente nos internatos, em que as meninas trocam apelidos carinhosos, escrevem-se bilhetinhos cheios de ternura, e às vezes se tornam amorosas das suas próprias mestras (RAMOS, 1939, p. 291).

\footnotetext{
${ }^{1}$ Grifo das autoras.
} 
Essa afirmação de Ramos e as demais responsabilidades de pais e, sobretudo, mães no surgimento da inversão sexual estão ancoradas em suas interpretações sobre os estudos de Sigmund Freud e sua teoria acerca da sexualidade feminina. Nesse sentido, pode-se dizer que a psicanálise freudiana também esteve presente nas considerações da pesquisadora Iracy Doyle sobre a homossexualidade feminina. Entretanto, ela não deixa de fazer algumas críticas em relação ao trabalho de Freud:

Para êle, a mulher não passava de um homem castrado, ansiado e deprimido pela falta do apêndice precioso. Incapaz de sentir a significação emocional das funções femininas, postulou que tôdas as realizações da mulher, até mesmo a maternidade, representavam esforços desesperados para compensar a castração biológica. Como diz a Dra. Clara Thompson, "Só um homem poderia exprimir-se dêsse modo em relação à mais nobre função feminina (DOYLE, 1956, p. 116).

Podemos observar que Doyle se utiliza da fala de sua orientadora, Dra. Clara Thompson, para relativizar o discurso de Freud. Essa importante revisão feita por Doyle sobre as bases da Psicanálise se fez presente nas suas conclusões e contribuições no tocante à homossexualidade feminina. Doyle (1956), ao analisar sua paciente (Carmen) e caracterizar as representações de seus pais, ressaltou (inicialmente o pai): “[...] era extremamente dominador, grosseiro, e não raro externava a opinião desfavorável que tinha das mulheres, consideradas por ele como criaturas inferiores" (DOYLE, 1956, p. 26). Segundo a psicanalista, os sentimentos que a paciente sentia pelo pai eram "medo, rebelião e inveja", enquanto que sobre sua mãe destaca: “A mãe de Carmen ocupava papel muito secundário na família: medrosa do marido, bastante devotada aos trabalhos da casa, era fria ou pouco demonstrativa" (DOYLE, 1956, p. 27). A partir destes dados, a psicanalista faz algumas afirmações a respeito da homossexualidade feminina:

Se o progenitor do sexo oposto molda a imagem do futuro objeto heterossexual, o progenitor do mesmo sexo serve de modelo à identificação pessoal. Identificação implica sempre em admiração. Conforme exprimia uma de minhas pacientes: - "Eu tinha que me identificar com o meu pai; todo mundo admirava-o, ao mesmo tempo que desprezava a minha mãe." - Portanto, para o desenvolvimento harmonioso da menina, é também imprescindível a presença, no grupo familiar, de uma figura feminina, maternal, que se imponha como exemplo a ser imitado; que interprete a feminilidade como algo digno quanto à masculinidade; que não se apresente como criatura humilhada de cabeça baixa, resignada e amedrontada, como a mãe de Carmem, capaz de desencorajar qualquer identificação, traduzida pela paciente como suicídio psicológico [...] (DOYLE, 1956, p. 107). 
Essas conclusões associam a origem da homossexualidade feminina como uma forma de rejeição à passividade percebida na figura materna e uma admiração e aproximação do poder e autoridade encontrados na figura paterna, logo, um modelo a ser seguido. Assim, contrariando as conclusões dos intelectuais que a antecederam, Doyle concluiu que:

No que concerne à atmosfera emocional do período formativo na neurose homossexual, consideramos como fatores favoráveis ao seu desenvolvimento tôdas as pressões culturais subscritas pelo ambiente do lar, capazes de levarem a menina a sentir ansiosamente a desvantagem da sua condição. Entretanto, os fatôres dinâmicos mais potentes são os que colorem as relações da criança com os progenitores de ambos os sexos. A personalidade materna deve ser de molde a estimular a identificação feminina. O pai oferece à filha a conceituação precoce - que persiste no plano emocional - dos representantes do outro sexo (DOYLE, 1956, p. 138).

Diferentemente das conclusões de Freud que associavam a homossexualidade feminina a um "complexo de castração", Doyle desloca essa compreensão do falo (biológico) e problematiza o modelo de homem e de mulher. Seguindo essa perspectiva, a "neurose" da homossexualidade deveria ser pensada a partir de outra ótica, uma vez que devem ser levados em conta os fatores culturais que envolvem o desenvolvimento das mulheres:

Sob pressões tão potentes, sujeita a limitações de toda a ordem, a mulher do grupo ocidental apresenta-se como algo complexo, em que se confunde o genuinamente biológico e o socialmente adquirido. A mulher é passiva, dizem os tratados clássicos; mas não se pode negar que a cultura lhe exige passividade, pois não reconhece o seu direito à agressão [...] A situação de dependência que a mulher deve aceitar, para viver de acordo com as instituições sociais, não pode ser assimilada sem ansiedade. Precisamos pensar que existe, em relação ao sexo feminino, verdadeira fusão entre o aspecto profissional e o amoroso. O marido é, ao mesmo tempo, o patrão, que paga indiretamente, com ou sem salário disfarçado em mesada (DOYLE, 1956, p. 128-129).

A problematização trazida por Doyle no excerto acima, e uma breve reflexão sobre os discursos proferidos pelos intelectuais homens do início do século $\mathrm{XX}$, nos leva a perceber o quanto era necessário reforçar, na perspectiva masculina, o lugar da mulher subalternizada através do reforço de práticas domésticas, inclusive como alternativa para reprimir o desenvolvimento da inversão sexual. No livro $A$ educação 
da mulher, Afrânio Peixoto (1936, p. 197) questiona: "Qual a vantagem de serem eleitoras, se nem sequer se pode experimentar possam ser boas deputadas, ou ministras, governadoras ou presidentes? Certo, houve boas rainhas; seguramente, não entronizadas por outras mulheres [...]".

Além de colocar em xeque a capacidade intelectual das mulheres, no pequeno excerto fica legível a intenção de Peixoto em condicioná-las ao espaço privado do lar, reforçando os espaços ocupados por homens e mulheres na sociedade: o espaço público destinado ao homem (racional) e o privado, à mulher (emotiva e frágil). Ao contrário de Peixoto, as reflexões trazidas por Doyle buscavam desestabilizar os discursos hegemônicos sobre as mulheres.

Mesmo atribuindo à homossexualidade o título de "problema", as contribuições de Doyle apresentavam a inversão sexual feminina como uma alternativa para as mulheres romperem com a condição passiva de esposas e mães. Esta interpretação ia à contramão dos demais cientistas que se comprometeram em estudar a homossexualidade feminina, os quais, em seus discursos, fortaleciam as atribuições de papéis pautados pelas diferenças biológicas, reforçando as representações sociais de homens e mulheres.

\section{Considerações finais}

Os discursos da intelectualidade aqui trazidos em diálogo com o de Doyle nos mostram o quanto residem intenções de que a população fosse disciplinada através de diferentes tecnologias e dispositivos com propósitos bem definidos. Tais propósitos correspondiam a esforços que visavam reforçar a heterossexualidade como algo natural. Pode-se dizer que, em sua grande maioria, acreditavam na importância da família, e mais ainda, nos papéis desempenhados por pais e mães na educação das crianças como fundamental para a prevenção da homossexualidade e reforço da sexualidade considerada e naturalizada como normal. Percebe-se, ainda, nos discursos defendidos pela intelectualidade, que a escola foi um espaço estratégico de definições/execuções político-institucionais de modelo de cidadania que, por sua vez, em um exercício de governo, visava regular e produzir corpos 
masculinos e femininos assimétricos e heterocentrados. A heterossexualidade assimétrica e androcêntrica era a meta social nos discursos científico-educativos entre as décadas de 1920 e 1950.

O discurso de Doyle convergia com o dos demais intelectuais no que diz respeito à caracterização da homossexualidade feminina como patologia, assim como a importância dos espaços educativos no seu surgimento. Entretanto, suas análises são discrepantes em relação aos condicionantes que levam ao desenvolvimento da chamada inversão sexual feminina. Enquanto os discursos dos intelectuais tentavam convencer de que a origem da homossexualidade feminina era oriunda de uma má criação que afastava a menina dos referenciais de feminilidade (então "naturais": sensível, maternal, subalternizada), a psicanalista Iracy Doyle, em uma atitude inovadora, afirmou o contrário: a homossexualidade feminina era uma possibilidade de subversão da mulher frente à determinação de uma vida passiva e resignada. Esse importante deslocamento de paradigma talvez tenha sido possível devido ao fato de ter sido desenvolvido por uma mulher em um espaço que até então era monopolizado de homens.

\section{Referências}

ALMEIDA, J. S. "Co-educação ou classes mistas? Indícios para a historiografia escolar (São Paulo - 1870-1930)”.: Rev. Bras. de Estud. Pedagógicos, v. 86, n. 213/214, p. 64-78, 2005.

CAETANO, M. Performatividades reguladas: heteronormatividade, narrativas biográficas e educação. Curitiba: Appris, 2016.

CAETANO, M.; BECK, D. Q. "Hommes de Letters e a homossexualidade: Discursos e pedagogias na primeira metade do século XX”. Revista Teias, v. 15, n. 38, p. 75-90, 2014.

CASTRO, V. Attentados ao pudor (Estudos sobre as aberrações do instinto sexual). Rio de Janeiro: Freitas Bastos, 1934.

CASTRO, E. Introdução a Foucault. São Paulo: Ed. Autêntica, 2014.

CORSETTI, B. “Análise documental no contexto da metodologia qualitativa." UNIrevista, v. 1, n. 1, p. 32-46, 2006.

COSTA, J. História da Psiquiatria no Brasil: um corte ideológico. Rio de Janeiro: Xenon, 1989.

DOYLE, I. Contribuições ao Estudo da homossexualidade feminina. Rio de Janeiro: Imago, 1956.

ELLIS, H. H. Inversão Sexual. São Paulo: Companhia Nacional, 1932. 
FISCHER, R. M. B. "Foucault e a análise do discurso em educação". Cadernos de Pesquisa, v. xx, n. 114, p. 197-223, 2001.

FOUCAULT, M. A Arqueologia do saber. Rio de Janeiro: Forense, 1986.

FOUCAULT, M. Vigiar e Punir. Petrópolis: Vozes, 1987.

FOUCAULT, M. Verdade e subjectividade. Revista de Comunicação e linguagem. $\mathrm{n}^{\circ}$ 19. Lisboa: Edições Cosmos, 1993. p. 203-223.

FOUCAULT, M. História da sexualidade I: a vontade de saber. Rio de Janeiro, Edições Graal, 1999.

FOUCAULT, M. "A ética do cuidado de si como prática da liberdade". In: Ditos e Escritos V. Ética, sexualidade e política, por Michel Foucault. Rio de Janeiro: Forense Universitária, 2004. p. 264-287.

MASSIMI, M. História das idéias psicológicas no Brasil, em obras do período colonial. São Paulo, 1984. Dissertação (Mestrado em Psicologia) — Universidade de São Paulo, São Paulo.

MOTTA, B. Homossexualismo em Medicina Legal. Rio de Janeiro: Tip. do Jornal do Comercio, 1937.

NEVES, M. Educação Sexual. Porto Alegre: Ed Globo, 1954.

NOGUEIRA, N. Lota Macedo Soares e Elizabeth Bishop: Amores e desencontros no Rio dos anos 1950-1960. Campinas: editora Apicuri, 2005.

PAUCHET, V. Os filhos - sua preparação para a vida. Rio de Janeiro: Civilização Brasileira, 1930.

PEIXOTO, A. Sexologia Forense. Rio de Janeiro: ed. Guanabara, 1934.

PEIXOTO, A. A educação da mulher. São Paulo: Cia Editora Nacional, 1936.

PEIXOTO, A. Eunice ou a educação da mulher. Rio de Janeiro: Jackson Inc. 1944. (Vol. XX).

RAMOS, A. A creança problema: A hygiene mental na Escola Primária. Rio de Janeiro: Cia. Ed. Nacional, 1939.

REIS, G. V. Sexologia e educação sexual no Brasil nas décadas de 1920-1950: um estudo sobre a obra de Francisco Albuquerque. 2006. Dissertação (Mestrado em Educação Escolar) Universidade Estadual Paulista Júlio de Mesquita Filho, Araraquara, 2006.

RIBEIRO, L. Homossexualidade e Endocrinologia. Rio de Janeiro: Francisco Alves, 1938.

RIBEIRO, L. "Problema médico legal do homossexualismo sob o ponto de vista endocrinológico". Revista Jurídica. v. 3, 1935.

ROSE, N. The politics of life itself. Theory. Culture \& Society, v. 18, n. 6, p. 1-30, 2001.

SCHMIDT, I. J. A orientação educacional. Porto Alegre: Ed. Globo, 1942.

STEPHANOU, M. "Discursos médicos e educação sanitária brasileira”. In: STEPHANOU, M.; BASTOS, M. H. C. (Org). Histórias e memórias da educaşão no Brasil. v. III: Século XX. Petrópolis, Rio de Janeiro: Vozes, 2009. 
STEKEL, W. Educação dos pais. Rio de Janeiro: Livraria José Olympio Editora, 1936.

SOIHET, R. Condição feminina e formas de violência: mulheres pobres e ordem urbana, 18901920. Rio de Janeiro: Forense Universitária, 1989.

RECEBIDO: $31 / 08 / 2020$

APROVADO: 03/10/2020

RECEIVED: 08/31/2020

APPROVED: $10 / 03 / 2020$

RECIBIDO: $31 / 08 / 2020$

APROBADO: 03/10/2020 